\title{
Are the studies on cancer risk from CT scans biased by indication? Elements of answer from a large-scale cohort study in France
}

\author{
N Journy ${ }^{1}$, J-L Rehel ${ }^{2}$, H Ducou Le Pointe ${ }^{3}, \mathrm{C} \mathrm{Lee}^{4}, \mathrm{H}_{\text {Brisse }}{ }^{5}$, J-F Chateil ${ }^{6}, \mathrm{~S} \mathrm{Caer-Lorho}^{1}$, D Laurier ${ }^{1}$ \\ and M-O Bernier ${ }^{\star}, 1$
}

${ }^{1}$ Laboratory of Epidemiology, Institute for Radiological Protection and Nuclear Safety, BP 17, 92262 Fontenay-aux-Roses, France; ${ }^{2}$ Medical Radiation Protection Expertise Unit, Institute for Radiological Protection and Nuclear Safety, BP 17, 92262 Fontenay-aux-Roses, France; ${ }^{3}$ Department of Paediatric Radiology, Trousseau University Hospital, 26 avenue du Docteur Arnold-Netter, 75012 Paris, France; ${ }^{4}$ Division of Cancer Epidemiology and Genetics, National Cancer Institute, National Institute of Health, 9000 Rockville Pike, 20892 Bethesda, MD, USA; ${ }^{5}$ Department of Radiology, Institut Curie, 11-13 rue Pierre et Marie Curie, 75005 Paris, France and ${ }^{6}$ Department of Paediatric Radiology, Pellegrin University Hospital, Place Amélie Raba-Léon, 33000 Bordeaux, France

Background: Recent epidemiological results suggested an increase of cancer risk after receiving computed tomography (CT) scans in childhood or adolescence. Their interpretation is questioned due to the lack of information about the reasons for examination. Our objective was to estimate the cancer risk related to childhood CT scans, and examine how cancer-predisposing factors (PFs) affect assessment of the radiation-related risk.

Methods: The cohort included 67274 children who had a first scan before the age of 10 years from 2000 to 2010 in 23 French departments. Cumulative $\mathrm{X}$-rays doses were estimated from radiology protocols. Cancer incidence was retrieved through the national registry of childhood cancers; PF from discharge diagnoses.

Results: During a mean follow-up of 4 years, 27 cases of tumours of the central nervous system, 25 of leukaemia and 21 of lymphoma were diagnosed; $32 \%$ of them among children with PF. Specific patterns of CT exposures were observed according to PFs. Adjustment for PF reduced the excess risk estimates related to cumulative doses from CT scans. No significant excess risk was observed in relation to $\mathrm{CT}$ exposures.

Conclusions: This study suggests that the indication for examinations, whether suspected cancer or PF management, should be considered to avoid overestimation of the cancer risks associated with CT scans.

Computed tomography (CT) is a valuable imaging technique to help diagnosis and medical management of some medical conditions. Nonetheless, its increasingly widespread use has raised concerns about potential risks of subsequent cancer, for CT leads to effective doses 5-20 times higher than conventional radiology
(Shrimpton et al, 1991; Mettler et al, 2008)-corresponding to organ doses of some units to tens of milligrays (mGy) from each scan. In 2007, there were 7.6 million CT examinations in France, overall, and 0.3 examinations per child aged younger than 10 years (Etard et al, 2012).

\section{*Correspondence: Dr M-O Bernier; E-mail: marie-odile.bernier@irsn.fr}

Received 4 June 2014; revised 8 September 2014; accepted 9 September 2014; published online 14 October 2014

(c) 2015 Cancer Research UK. All rights reserved 0007-0920/15 
A reasonable quantitative assessment of potential risks induced by radiation exposure is required to enable physicians to make appropriate decisions about radiology examinations and to provide patients and families with adequate information. One initial approach to such an assessment is to use robust epidemiological results obtained at higher doses to predict the cancer risks related to these low-dose exposures. Although this approach makes it possible to estimate an expected magnitude of potential risks (Brenner and Hall, 2007; Ivanov et al, 2012; Krille et al, 2012; Calandrino et al, 2013; Miglioretti et al, 2013; Journy et al, 2014), its validity has been widely debated in view of hypotheses underlying those extrapolations, in particular of a no-threshold relation between cancer risk and radiation exposure (Brenner and Sachs, 2006; Mothersill and Seymour, 2013; Preston et al, 2013).

Thus, recent studies have been conducted (Pearce et al, 2012; Mathews et al, 2013; Huang et al, 2014) or are underway (Krille et al, 2012; Meulepas et al, 2014) to provide direct risk estimates, from large populations exposed to CT scans. The UK study showed a risk of intracranial tumours and leukaemia three times higher in children and young adults who received mean organ doses of 50 and $60 \mathrm{mGy}$, respectively, in comparison with patients exposed to doses $<5 \mathrm{mGy}$, after 7-10 years of follow-up on average (Pearce et al, 2012). The Australian study, with a mean follow-up of 9.5 years, reported excess risks of cancer at several sites, and an increase of about $20 \%$ in the risk of all cancers, compared with individuals not exposed to CT scans (Mathews et al, 2013). Finally, the Taiwan study suggested a risk of brain tumours in children and adolescents who had head CT scans 2.6 times higher than among unexposed individuals, after 8 years of follow-up (Huang et al, 2014). The leukaemia results were consistent with those expected by extrapolation from previous epidemiological results at higher doses (Hall and Brenner, 2012). However, the risk estimates for tumours of the central nervous system (CNS) were substantially higher than those estimated per unit of dose from moderate- and high-dose studies. The interpretation of these recent results is nevertheless limited by the lack of information about the reasons for scans (UNSCEAR, 2013; Walsh et al, 2014). Overestimates could easily have resulted if these examinations were performed either because of suspected cancer (reverse causation) or for diagnosis or monitoring of conditions themselves related to increased cancer risk (confounding bias). In the absence of information about the indication for the examination, delaying the estimation of cancer incidence beyond various periods of exclusion is one way to assess the consistency of the results when the probability of reverse causation is reduced. The only way to address the confounding bias, however, is to collect data about predisposing factors (PFs) to cancer, such as genetic syndromes and immune deficiencies.

A French retrospective cohort study ('Cohorte Enfant Scanner') is currently assessing cancer risks after CT scans during childhood (Bernier et al, 2012b). To obtain estimates of radiation-related risks not biased by potential confounding factors, it is identifying major PFs among the exposed children. This paper presents preliminary estimates of the risks of CNS cancers, leukaemia and lymphoma, and examines both the possibility of reverse causation and the effect of some genetic defects and other cancerpredisposing conditions on the assessment of the risks attributable to CT scans.

\section{SUBJECTS AND METHODS}

Inclusion of children. The cohort includes children born after 1 January 1995 who had a first CT scan before the age of 10 years from 1 January 2000 to 31 December 2010, and had no cancer diagnosis at the first scan. Scans took place in 21 French university hospitals-corresponding to 23 radiology departments with a high volume of paediatric patients-throughout the country, including one in an overseas district. Patients living outside the territory covered by the French national registry of childhood cancers (Registre National des Cancers de l'Enfant (RNCE)) (or who had a CT scan in the overseas department before 2004), even for a limited period, were excluded to ensure correct identification of cancer diagnoses.

Data on CT exposure. Information about exposures to CT scans was retrieved through the electronic radiology information system (RIS) of each department. In one hospital, that information was collected, however, from the hospital discharge database of the Programme de Médicalisation des Systèmes d'Information Médicale (PMSI), which also furnished information for another facility to complete the exposure data for the last year of follow-up. Data were also extracted from the Picture Archiving and Communication System of a third hospital, which had not stored RIS data for the entire study period; agreement between the two sources of information was good for the 4 years of overlap. The following data were collected: patient identifiers, sex, birth date, postal code of birth place, postal code of residence ( $92 \%$ complete), date and type of examination (anatomical area explored, number of sequences of image acquisition for each body part). Linkage of patient identifiers through the different sources of information enabled identification of children who were examined in several departments.

Follow-up. The children were followed from the date of their first CT scan until their exit date, which was the earliest of 31 December 2011, death, first cancer diagnosis, or their 15th birthday. Those whose exit date came before the end of the exclusion period were thus removed from the analyses. Vital status was obtained by linkage with the national registry for the identification of individuals (Registre National d'Identification des Personnes Physiques (RNIPP)).

Case ascertainment. The RNCE has recorded all diagnoses of haematological malignancies, including lymphomas, since 1990, and of solid tumours (all malignancies as well as some borderline/ benign tumours, especially of the CNS) since 2000, for the residents of metropolitan (European) France younger than 15 years (Lacour et al, 2010). Linkage with the RNCE enabled us to find diagnoses preceding the first CT scan (to exclude those children) and all incident cases to 31 December 2011. Patients with only a diagnosis of a second tumour recorded in the registry were systematically excluded from the study. For the children living in the overseas department, who were not covered by the national registry, cancer diagnoses were retrieved through the PMSI of the hospital (the only oncology department in the area; some data were available from 1995, with coverage exhaustive starting in 2004), each confirmed afterwards by checking the patients' medical records. Most of the cancer diagnoses for children who lived in this district were nevertheless registered in the RNCE after they were transferred to a hospital in metropolitan France for diagnostic confirmation and/or cancer treatment. Cases of cancer were defined as malignant diseases or CNS tumours regardless of the histology. Topography codes 70-71, 722-729, 751-753 of the International Classification of Diseases (ICD) for Oncology-3rd revision-defined CNS tumours; the morphology codes used for leukaemia (including myelodysplasia) and lymphoma are detailed in Supplementary Table 1. The RNCE also provided the time to diagnosis, defined as the time from the onset of the first symptoms reported by the parents and the date of diagnosis (histological confirmation) (Dang-Tan and Franco, 2007).

Identification of PFs. The list of syndromes or diseases predisposing children to CNS cancer, leukaemia, and lymphoma (Table 1) was determined by experts in paediatric oncology after a literature review. The PF of interest were retrieved among 
Table 1. Predisposing factors for CNS cancer, leukaemia, and lymphoma identified by diagnoses in hospital discharge databases and their frequency in 67274 children included in the cohort

\begin{tabular}{|c|c|c|c|c|c|c|}
\hline & \multicolumn{3}{|c|}{ Predisposing factor for cancer } & & \multicolumn{2}{|c|}{ Frequency in the cohort } \\
\hline & $\begin{array}{c}\text { CNS } \\
\text { tumours }\end{array}$ & Leukaemia & Lymphoma & ICD-10 codes & $\begin{array}{c}\text { No } \\
\text { children }\end{array}$ & (Per 1000) \\
\hline \multicolumn{7}{|l|}{ Genetic defects } \\
\hline $\begin{array}{l}\text { Familial adenomatous polyposis } \\
\text { Retinocytoma } \\
\text { Multiple endocrine neoplasia (MEN1, MEN2) } \\
\text { Fanconi anaemia }^{\text {a }} \\
\text { Ataxia telangiectasia }^{\text {a }} \\
\text { Xeroderma pigmentosum } \\
\text { Bloom syndrome } \\
\text { Neurofibromatosis (NF1, NF2) } \\
\text { Other phacomatoses } \\
\text { Noonan syndrome } \\
\text { Down syndrome } \\
\text { Klinefelter syndrome }\end{array}$ & $\begin{array}{l}x \\
x \\
x\end{array}$ & $\begin{array}{l}X \\
X \\
X \\
X \\
\\
X \\
X\end{array}$ & $\begin{array}{l}x \\
x \\
x\end{array}$ & $\begin{array}{l}\text { D12.6 } \\
\text { D31 } \\
\text { D44.8 } \\
\text { D61.0 } \\
\text { G11.3 } \\
\text { Q82.1 } \\
\text { Q82.8 } \\
\text { Q85.0 } \\
\text { Q85.1-Q85.9 } \\
\text { Q87.1 } \\
\text { Q90 } \\
\text { Q98 }\end{array}$ & $\begin{array}{r}20 \\
62 \\
3 \\
63 \\
8 \\
10 \\
30 \\
106 \\
192 \\
94 \\
202 \\
15\end{array}$ & $\begin{array}{l}(0.3) \\
(0.9) \\
(<0.1) \\
(0.9) \\
(0.1) \\
(0.1) \\
(0.4) \\
(1.6) \\
(2.9) \\
(1.4) \\
(3.0) \\
(0.2)\end{array}$ \\
\hline \multicolumn{7}{|l|}{ Immune deficiencies } \\
\hline $\begin{array}{l}\text { HIV/AIDS } \\
\text { Severe combined immune deficiency (SCID) } \\
\text { Wiskott-Aldrich syndrome } \\
\text { Common variable immune deficiency (CVID) } \\
\text { Transplantation }\end{array}$ & & $\begin{array}{l}X \\
x \\
x \\
x\end{array}$ & $\begin{array}{l}X \\
X \\
X \\
X \\
X\end{array}$ & $\begin{array}{l}\text { B20-B24, R75, Z21 F02.4, O98.7 } \\
\text { D81.0-D81.2 } \\
\text { D82.0 } \\
\text { D83 } \\
\text { N16.5, T86 Y83.0, Z94 }\end{array}$ & $\begin{array}{r}245 \\
64 \\
17 \\
57 \\
749\end{array}$ & $\begin{array}{c}(3.6) \\
(1.0) \\
(0.3) \\
(0.8) \\
(11.1)\end{array}$ \\
\hline
\end{tabular}

children hospitalised at least once in the hospitals involved in the study, from discharge diagnoses (coded according to ICD-10th revision) recorded in the hospitals' PMSI (discharge database). Those diagnoses were collected regardless of the date of hospitalisation or the performance of any radiology examination at that time. The use of discharge diagnoses to identify PF has previously been assessed (Bernier et al, 2012a). Diagnoses in the RNCE with morphology codes 9384/1 (topography code 692) and 9540/1 (all sites) were also considered to identify, respectively, children with retinocytoma and neurofibromatosis.

Assessment of organ doses. Dose reconstruction was based on the radiological protocols defined by each department-941 protocols for the most common procedures defining image-acquisition parameters for several patient age (or weight) categories. Effective, brain and red bone marrow (RBM) doses were estimated using a dosimetry method, where a series of computational human phantoms were coupled with a reference CT scanner model simulated within a Monte Carlo transport code, MCNPX2.7 (Lee et al, 2012). The dosimetry method was experimentally validated using paediatric and adult physical phantoms (Long et al, 2013). Estimated organ doses are based on an original library of anatomically realistic computational reference phantoms for: newborns, and 1-, 5- and 10-year-olds (Lee et al, 2010), and interpolated for intermediate ages at examination. For all protocols, the scan ranges were standardised over each phantom. Doses from scans of the limbs and shoulders were set at 0 ; those from scans of the femur were considered equal to doses for the pelvic region. When no protocol was available in the department for a specific procedure, the median dose values estimated for the other departments using the same CT machine were applied; if not available, the median dose values for the other single-detector CT or multi-detector CT machines were assigned. Because very few protocols were available for spine and cervical region scans, median doses for all machines were used. Overall, for $86.8 \%$ of the examinations, the doses were estimated according to the specific protocol used at examination.
Data analysis. Analyses were restricted to the cancer sites for which we considered the number of incident cases as sufficient, that is, CNS cancer, leukaemia, and lymphoma. Potential risks of cancer were assessed, first, according to the presence of PF and, then, according to cumulative CT X-ray doses to the brain (for CNS cancer) and to the RBM (for leukaemia and lymphoma). The $\mathrm{RBM}$ dose here was considered as a surrogate for exposure to various haematopoietic tissues. For CNS tumours, the doseresponse analysis was conducted for two end points: the diagnosis confirmed by histology (the primary end point), and the onset of first signs or symptoms of cancer (the secondary end point). The second criterion ensures that the estimated cumulative doses did not result from CT scans performed for a suspected tumour diagnosed later. For haematopoietic tumours, frequent missing data on time to diagnosis prevented the performance of secondary analyses; only the primary end point was considered.

Relative risks (RRs) for PF were estimated by Poisson models (Breslow and Day, 1987) adjusted for the following covariates: sex, period of birth (1995-2001, 2002-2010), attained age (in years), and time since entry into the cohort (in years). Excess RRs (ERRs) per unit of cumulative organ dose were also estimated with Poisson models, where the background risk of cancer incidence (without exposure to CT scans) was described by the same covariates and the presence of any PF (yes/no) (or the presence of a specific PF in further analyses) (see Supplementary Table 2 for detailed risk models). To investigate the possibility that children were scanned because of a suspected cancer diagnosed later, exclusion periodsduring which cancer incidence was not counted-and cumulative dose lagging of, both, 1-4 years were applied. For the analysis of the secondary end point (the onset of first symptoms of CNS tumours), the exclusion period and dose lagging were both set at 1 year. To assess the consistency of the principal results in relation to the ascertainment of cases, sensitivity analyses were conducted by removing children born before 1 January 2000, with at least one CT scan in the overseas district or without any residential data.

Risk estimates were computed by the maximum likelihood method; the confidence intervals (CIs) of the RRs were determined from the likelihood profiles (LPs). For ERR estimates, (left biased) 
Wald CIs are presented here because of usual computational problems in defining LP-based CIs when the number of cases and the potential excess risk are small. We used SAS software (SAS Institute, Cary, NC, USA, Version 9.2) to build data sets with exact computation of person-years (PY) and Epicure software (HiroSoft International Corporation, Seattle, WA, USA, Version 1.4, module AMFIT) (Preston et al, 1993) to perform risk analyses.

\section{RESULTS}

Study population. Among children eligible for the study and traced in the RNIPP, $1.5 \%$ were excluded because missing information on the body part scanned at all examinations prevented dose estimation, and $13.4 \%$ because their follow-up did not exceed 1 year. After these prior exclusions, 67 274, 58620 , 50134 , and 41926 children were included for analyses with exclusion periods of, respectively, 1, 2, 3, and 4 years. Girls accounted for $42.9 \%$ of all included children. In the overall study population, $366(0.5 \%)$ patients were identified as at risk of CNS cancer, $1162(1.7 \%)$ at risk of leukaemia, and $1091(1.6 \%)$ at risk of lymphoma. Detailed frequencies are given in Table 1 . The overall duration of follow-up was 4.4 years in average (median: 4.1 years); it did not substantially differ according to the presence of PF (Table 2). The annual mortality rate was 128 per 100000 children with no PF but substantially higher for the children predisposed to CNS tumours (252 per 100000 PY), leukaemia (1543 per 100000 PY) or lymphoma (1259 per 100000 PY).

Computed tomography scan exposures according to PFs. Depending on the exclusion period, the analyses considered 93640 (1 year), 81261 (2 years), 68847 (3 years), and 57057 (4 years) CT scans. The examinations were of the brain/skull (56.9\%), chest $(23.1 \%)$, sinus and/or middle ear (11.7\%), abdomen and/or pelvis (9.1\%), cervical region (3.0\%), limbs (1.7\%), and spine (1.4\%) (one CT scan could have explored several body parts). For the overall study period (1-year exclusion), children were exposed to median doses of $18.3 \mathrm{mGy}$ to the brain and $6.9 \mathrm{mGy}$ to the RBM (Table 2). Overall 32.3 and $40.5 \%$, respectively, received cumulative tissue doses to the brain and the RBM $<5 \mathrm{mGy}$, whereas 2.1 and $0.2 \%$, respectively, were exposed to doses $>100 \mathrm{mGy}$.

Children at risk of CNS cancer received a first examination at almost the same ages as children without PF (3.2 years $v s 3.4$ in average) but received more scans (1.8 vs 1.4 in average) and higher cumulative brain doses ( $33 \mathrm{mGy} v s 23 \mathrm{mGy}$ in average) (Table 2). The proportion of highly exposed children was also larger in the presence of PF; $12.0 \%$ of the patients predisposed to CNS cancer received cumulative brain doses $>95$ th percentile (68.0 mGy).

Children with PF for leukaemia or lymphoma were younger at the first examination (2.9 years in average) and underwent more

Table 2. Characteristics of CT scan exposures in the study population according to the presence of PFs for cancer

\begin{tabular}{|c|c|c|c|c|c|}
\hline & \multicolumn{5}{|c|}{ Predisposing factors for cancer } \\
\hline & Overall & None & CNS cancer & Leukaemia & Lymphoma \\
\hline Number of children & 67274 & 65512 & 366 & 1162 & 1091 \\
\hline Person-years & 296863 & 288747 & 1585 & 4990 & 5402 \\
\hline Mean follow-up in years (s.d.) & $4.4(2.9)$ & $4.4(2.9)$ & $4.3(2.8)$ & $4.3(2.8)$ & $5.0(2.9)$ \\
\hline Mean age at the 1st CT scan in years (s.d.) & $3.4(2.9)$ & $3.4(2.9)$ & $3.2(2.9)$ & $2.9(2.7)$ & $2.9(2.7)$ \\
\hline \multicolumn{6}{|l|}{ Age at the 1 st CT scan (\%) } \\
\hline $\begin{array}{l}<1 \text { month } \\
\geqslant 1 \text { month }-<1 \text { year } \\
1-4 \text { years } \\
5-9 \text { years }\end{array}$ & $\begin{array}{r}6.0 \\
24.8 \\
40.1 \\
29.1\end{array}$ & $\begin{array}{r}6.0 \\
24.6 \\
40.1 \\
29.3\end{array}$ & $\begin{array}{r}6.0 \\
29.2 \\
37.2 \\
27.6\end{array}$ & $\begin{array}{r}3.3 \\
31.4 \\
42.5 \\
22.8\end{array}$ & $\begin{array}{r}5.0 \\
29.0 \\
42.7 \\
23.3\end{array}$ \\
\hline \multicolumn{6}{|l|}{ Total number of CT scans } \\
\hline $\begin{array}{l}\text { Mean (s.d.) } \\
\text { Median }\end{array}$ & $\begin{array}{c}1.4(1.2) \\
1.0\end{array}$ & $\begin{array}{c}1.4(1.2) \\
1.0\end{array}$ & $\begin{array}{c}1.8(1.9) \\
1.0\end{array}$ & $\begin{array}{c}2.4(2.6) \\
2.0\end{array}$ & $\begin{array}{c}2.5(2.7) \\
2.0\end{array}$ \\
\hline \multicolumn{6}{|l|}{ Cumulative effective dose $(\mathrm{mSv})^{a}$} \\
\hline $\begin{array}{l}\text { Mean (s.d.) } \\
\text { Median }\end{array}$ & $\begin{array}{c}4.1(5.2) \\
2.6\end{array}$ & $\begin{array}{c}3.9(4.8) \\
2.6\end{array}$ & $\begin{array}{c}5.7(6.6) \\
3.1\end{array}$ & $\begin{array}{c}10.0(14.5) \\
5.8\end{array}$ & $\begin{array}{c}10.6(14.9) \\
6.2\end{array}$ \\
\hline \multicolumn{6}{|l|}{ Cumulative brain dose (mGy) } \\
\hline $\begin{array}{l}\text { Mean (s.d.) } \\
\text { Median }\end{array}$ & $\begin{array}{c}23.1(31.8) \\
18.3\end{array}$ & $\begin{array}{c}23.2(31.5) \\
18.6\end{array}$ & $\begin{array}{c}33.0(51.3) \\
22.4\end{array}$ & $\begin{array}{c}18.7(40.5) \\
0.9\end{array}$ & $\begin{array}{c}19.7(37.8) \\
1.6\end{array}$ \\
\hline \multicolumn{6}{|l|}{ Cumulative RBM dose (mGy) } \\
\hline $\begin{array}{l}\text { Mean (s.d.) } \\
\text { Median }\end{array}$ & $\begin{array}{c}8.9(10.7) \\
6.9\end{array}$ & $\begin{array}{c}8.8(10.5) \\
6.9\end{array}$ & $\begin{array}{c}12.5(16.5) \\
8.4\end{array}$ & $\begin{array}{c}10.4(15.4) \\
5.8\end{array}$ & $\begin{array}{c}10.9(14.6) \\
6.2\end{array}$ \\
\hline Number of CT scans & 93640 & 89722 & 672 & 2822 & 2747 \\
\hline \multicolumn{6}{|l|}{ Anatomical region explored $(\%)^{b}$} \\
\hline $\begin{array}{l}\text { Brain/skull } \\
\text { Sinus and/or middle ear } \\
\text { Cervical region (except spine) } \\
\text { Chest } \\
\text { Abdomen and/or pelvis } \\
\text { Spine } \\
\text { Limbs }\end{array}$ & $\begin{array}{r}56.9 \\
11.7 \\
3.0 \\
23.1 \\
9.1 \\
1.4 \\
1.7\end{array}$ & $\begin{array}{r}57.9 \\
11.8 \\
3.0 \\
22.5 \\
8.2 \\
1.4 \\
1.7\end{array}$ & $\begin{array}{r}63.8 \\
10.3 \\
3.0 \\
15.6 \\
13.2 \\
1.6 \\
1.6\end{array}$ & $\begin{array}{r}23.8 \\
8.8 \\
2.7 \\
44.1 \\
37.8 \\
1.0 \\
0.9\end{array}$ & $\begin{array}{r}25.4 \\
8.0 \\
2.5 \\
43.2 \\
38.8 \\
0.7 \\
0.8\end{array}$ \\
\hline \multicolumn{6}{|c|}{$\begin{array}{l}\text { Abbreviations: CNS = central nervous system; CT = computed tomography; RBM = red bone marrow. The categories of predisposing factors (defined for each specific site of cancer) are not } \\
\text { exclusive, as children may be at risk of cancer at several sites. The results are given for an exclusion period of } 1 \text { year. } \\
{ }^{a} \text { Conversion factors from the ICRP } 103 \text {. } \\
{ }^{b_{\text {Each }}} \text { single CT scan could have explored several body parts. }\end{array}$} \\
\hline
\end{tabular}


scans (2.5 in average) than patients without PF (Table 2). They were mainly exposed for scanning of the thoracic or the abdominal region (43.6 vs $22.4 \%$ of the CT scans performed in patients without PF or having PF for CNS tumours only) resulting in the highest effective doses. Despite of the total number of scans, patients with PF for leukaemia or lymphoma received similar cumulative RBM doses than patients without PF due to a lower proportion of head scans. The patterns of CT exposures varied, however, according to each PF (Supplementary Table 3).

Cancer incidence and risks associated with PFs. During the overall study period, 106 children were diagnosed with a primary tumour, including 27 with CNS cancer (of which 14 malignant diseases), 25 with leukaemia, and 21 with lymphoma. Supplementary Table 4 details the incidence of CNS cancer, leukaemia, and lymphoma by histological subgroups for various exclusion periods. Other incident cases were neuroblastoma $(n=8)$, kidney tumours $(n=8)$, liver tumours $(n=3)$, retinoblastoma $(n=2)$, and tumours of other sites $(n=12)$. Incidence rates (IRs) of CNS cancer (about 9-10 per 100,000 PY) did not vary substantially with the exclusion period; for leukaemia, however, IR decreased from 8.4 to 5.3 per $100000 \mathrm{PY}$, and for lymphoma, it increased from 7.1-9.0 per $100000 \mathrm{PY}$, for 1-4 years of exclusion

\begin{tabular}{|c|c|c|c|}
\hline & & \multicolumn{2}{|c|}{ Time to diagnosis (weeks) } \\
\hline & $\begin{array}{c}\text { Number of } \\
\text { cases }\end{array}$ & Median & $\begin{array}{l}\text { Value for } \\
\text { each case }\end{array}$ \\
\hline Overall & 27 & 8 & \\
\hline Pilocytic astrocytoma & 2 & 35 & 5,64 \\
\hline $\begin{array}{l}\text { Other astrocytic and } \\
\text { oligodendroglial tumours }\end{array}$ & 5 & 3 & $1,1,4,8, N A^{*}$ \\
\hline $\begin{array}{l}\text { Neuronal and mixed } \\
\text { neuronal-glial tumours }\end{array}$ & 4 & 65 & $30,65,67, N A^{*}$ \\
\hline Medulloblastoma & 7 & 4 & $1,2,4,4,8,17, \mathrm{NA}$ \\
\hline Meningioma & 2 & 92 & 27,156 \\
\hline Other & 7 & 25 & $\begin{array}{c}2,4,13,36,104 \\
260, N^{*}\end{array}$ \\
\hline
\end{tabular}

(Supplementary Table 4). Median time from first symptoms to diagnosis of CNS cancer was 8 weeks but varied depending on the histology (Table 3 ). It exceeded 1 year for $9(34.6 \%)$ children and 3 years for $4(15.4 \%)$ (the time to diagnosis was unknown for one case). On the basis of a 2-year exclusion period, the RRs were 86.8 (95\% CI 33.1-205.9) for CNS cancer, 24.2 (95\% CI 7.7-65.2) for leukaemia, and 31.7 (95\% CI 13.9-68.4) for lymphoma in patients with PF compared with children without them (Table 4).

Computed tomography scans-related risks of cancer. For all the outcomes, the adjustment for PF lowered the estimates of ERR associated with the cumulative organ doses from CT scans (Table 5). The adjustment for each single PF led to different estimates of the ERR per mGy.

For an exclusion period of 2 years after the first CT scan and adjusting for all PFs, the ERR per mGy was 0.012 (95\% CI - 0.013 to 0.037 ) for CNS cancer, 0.047 (95\% CI -0.065 to 0.159 ) for leukaemia, and 0.008 (95\% CI -0.057 to 0.073 ) for lymphoma. Although a dose-response trend was suggested for the risk of CNS cancer (but not for haematopoietic cancers) (Supplementary Table 5), no significant effect was actually observed.

For haematopoietic tumours, the ERR increased with the exclusion period (Table 6). Inversely, for CNS cancer, the ERR tended towards 0 when the exclusion period was 3 years or longer. The adjusted ERR of CNS cancer per $\mathrm{mGy}$ up to the onset of the first symptoms (the secondary end point), that is, 0.007 (95\% CI -0.017 to 0.032 ), was lower than the estimate for the primary end point with a 2-year exclusion period, even after adjusting for PF (Table 5). The modifying effects of characteristics at exposure, attained age, and time since examination on the estimates of ERR (for the primary end points) are presented in Supplementary Table 6. Supplementary Table 7 reports the results of the sensitivity analyses.

\section{DISCUSSION}

This paper reports the frequency of different PF in children who underwent CT scans in France and examines the impact of those predisposing conditions on preliminary estimates of radiationrelated risks in the Cohorte Enfant Scanner. In this population, 0.5, 1.7 , and $1.6 \%$ of children, respectively, had medical conditions known to predispose them to CNS cancer, leukaemia, and lymphoma. Subsequently to RRs of 87 (95\% CI 33-206) (CNS

Table 4. Number of cases ( $N$ ) of primary CNS tumours of the CNS, leukaemia, and lymphoma, incidence rates (IRs) per 100000 PY, and relative risks (RRs) of cancers associated with PFs

\begin{tabular}{|c|c|c|c|c|c|c|c|c|c|c|c|c|}
\hline \multirow[b]{2}{*}{ Predisposing factors } & \multicolumn{4}{|c|}{ CNS cancer } & \multicolumn{4}{|c|}{ Leukaemia } & \multicolumn{4}{|c|}{ Lymphoma } \\
\hline & $\mathbf{N}$ & IR & RR & $(95 \% \mathrm{Cl})$ & $\mathbf{N}$ & IR & RR & $(95 \% \mathrm{Cl})$ & $\mathbf{N}$ & IR & RR & $(95 \% \mathrm{Cl})$ \\
\hline None & 15 & 6 & 1 & Reference & 12 & 5 & 1 & Reference & 12 & 5 & 1 & Reference \\
\hline All specific PF & 7 & 566 & 86.8 & $(33.1 ; 205.9)$ & 5 & 128 & 24.2 & $(7.7 ; 65.2)$ & 7 & 160 & 31.7 & $(13.9 ; 68.4)$ \\
\hline NF1, NF2 & 5 & 1389 & 206.0 & $(67.2 ; 526.8)$ & NA & & & & NA & & & \\
\hline Other phacomatoses & 3 & 493 & 59.2 & $(13.9 ; 174.2)$ & NA & & & & NA & & & \\
\hline Retinocytoma & 1 & 448 & 45.8 & $(2.5 ; 219.9)$ & NA & & & & NA & & & \\
\hline Down syndrome & NA & & & & 1 & 175 & 24.4 & $(1.3 ; 120.5)$ & NA & & & \\
\hline CVID, SVID & NA & & & & 1 & 252 & 36.9 & $(2.0 ; 181.2)$ & 0 & 0 & 0.0 & - \\
\hline Transplantation & NA & & & & 4 & 152 & 26.8 & $(7.5 ; 75.8)$ & 5 & 190 & 31.4 & $(10.1 ; 82.3)$ \\
\hline Ataxia telangiectasia & NA & & & & 0 & 0 & 0.0 & - & 2 & 5717 & 597.1 & $(91.7 ; 2241)$ \\
\hline \multicolumn{13}{|c|}{$\begin{array}{l}\text { Abbreviations: } 95 \% \mathrm{Cl}=\text { likelihood profile-based } 95 \% \text { confidence intervals; } \mathrm{CNS}=\text { central nervous system; } \mathrm{CVID}=\text { common variable immune deficiency; IR=incidence rate per } 100000 \text { person- } \\
\text { years; } \mathrm{NA}=\text { not applicable (the disease does not particularly predispose the affected individuals to cancer at that site; NF1, NF2 = neurofibromatosis type 1, type 2; PF= factors predisposing } \\
\text { specifically to cancer at that site; RR = relative risk; } \mathrm{SVID}=\text { severe combined immune deficiency. RRs are estimated by Poisson models (maximum likelihood estimates) adjusted for gender, } \\
\text { period of birth (1995-2001, 2002-2010), attained age (in years), and time since entry into the cohort (in years). The results are given for an exclusion period of } 2 \text { years. No cancer was diagnosed in } \\
\text { the patients affected by the other predisposing factors considered in the study. }\end{array}$} \\
\hline
\end{tabular}


Table 5. Excess relative risks (ERRs) of CNS tumour, leukaemia, and lymphoma related to cumulative organ doses in mGy, adjusted or not for the presence of PFs for cancer for the primary and secondary end points

\begin{tabular}{|c|c|c|c|c|c|c|}
\hline & \multicolumn{2}{|c|}{ CNS cancer } & \multicolumn{2}{|c|}{ Leukaemia } & \multicolumn{2}{|c|}{ Lymphoma } \\
\hline & ERR & $(95 \% \mathrm{Cl})$ & ERR & $(95 \% \mathrm{Cl})$ & ERR & $(95 \% \mathrm{Cl})$ \\
\hline \multicolumn{7}{|c|}{ Primary end point (2-year exclusion period) } \\
\hline $\begin{array}{l}\text { Not adjusted for any PF } \\
\text { Adjusted for all specific PF } \\
\text { Adjusted for one specific PF } \\
\text { NF1, NF2 } \\
\text { Other phacomatoses } \\
\text { Retinocytoma } \\
\text { Down syndrome } \\
\text { CVID, SVID } \\
\text { Transplantation } \\
\text { Ataxia telangiectasia }\end{array}$ & $\begin{array}{c}0.022 \\
0.012 \\
0.019 \\
0.014 \\
0.020 \\
\text { NA } \\
\text { NA } \\
\text { NA } \\
\text { NA }\end{array}$ & $\begin{array}{l}(-0.016 ; 0.061) \\
(-0.013 ; 0.037) \\
(-0.016 ; 0.053) \\
(-0.015 ; 0.042) \\
(-0.016 ; 0.057)\end{array}$ & $\begin{array}{l}0.057 \\
0.047 \\
\text { NA } \\
\text { NA } \\
\text { NA } \\
0.068 \\
0.054 \\
0.045 \\
\text { NA }\end{array}$ & $\begin{array}{l}(-0.079 ; 0.193) \\
(-0.065 ; 0.159) \\
\\
(-0.087 ; 0.222) \\
(-0.076 ; 0.184) \\
(-0.065 ; 0.155)\end{array}$ & $\begin{array}{l}0.018 \\
0.008 \\
\text { NA } \\
\text { NA } \\
\text { NA } \\
\text { NC } \\
\text { NC } \\
0.008 \\
-0.010\end{array}$ & $\begin{array}{l}(-0.068 ; 0.104) \\
(-0.057 ; 0.073)\end{array}$ \\
\hline \multicolumn{7}{|l|}{ Secondary end point } \\
\hline $\begin{array}{l}\text { Not adjusted for any PF } \\
\text { Adjusted for all specific PF }\end{array}$ & $\begin{array}{l}0.015 \\
0.007\end{array}$ & $\begin{array}{l}(-0.022 ; 0.052) \\
(-0.017 ; 0.032)\end{array}$ & Not available & & Not available & \\
\hline \multicolumn{7}{|c|}{ 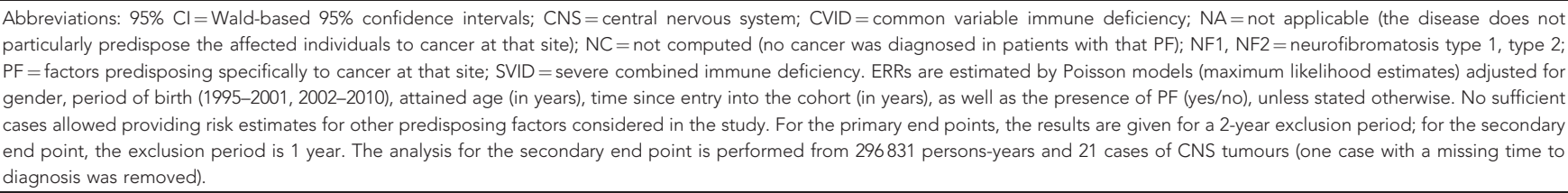 } \\
\hline
\end{tabular}

Table 6. Number of cases ( $N$ ) and excess relative risks (ERRs) of primary tumours of the CNS, leukaemia, and lymphoma related to cumulative organ doses in $\mathrm{mGy}$, adjusted for the presence of PFs for specific cancers, for exclusion periods of 1, 2, 3, and 4 years

\begin{tabular}{|c|c|c|c|c|c|c|c|c|c|c|c|c|}
\hline & & & 1 & & & 2 & & & 3 & & & 4 \\
\hline Exclusion period (years) & $N$ & ERR & $(95 \% \mathrm{Cl})$ & $N$ & ERR & $(95 \% \mathrm{Cl})$ & $N$ & ERR & $(95 \% \mathrm{Cl})$ & $N$ & ERR & $(95 \% \mathrm{Cl})$ \\
\hline CNS cancer & 27 & 0.017 & $(-0.010 ; 0.044)$ & 22 & 0.012 & $(-0.013 ; 0.037)$ & 17 & 0.000 & $(-0.014 ; 0.014)$ & 13 & -0.004 & $(-0.011 ; 0.001)$ \\
\hline Leukaemia & 25 & 0.014 & $(-0.037 ; 0.065)$ & 17 & 0.047 & $(-0.065 ; 0.159)$ & 12 & 0.056 & $(-0.101 ; 0.214)$ & 7 & 0.510 & $(-2.129 ; 3.149)$ \\
\hline Lymphoma & 21 & -0.002 & $(-0.050 ; 0.046)$ & 19 & 0.008 & $(-0.057 ; 0.073)$ & 14 & 0.062 & $(-0.102 ; 0.227)$ & 12 & 0.048 & $(-0.108 ; 0.205)$ \\
\hline
\end{tabular}

cancer), 24 (95\% CI 8-65) (leukaemia), and 32 (95\% CI 14-68) (lymphoma), children with PF accounted for $32 \%$ of all tumours diagnosed during the study period (Table 4). Specific patterns of CT exposures were observed according to the PFs. In particular, children with PF for hematopoietic tumours received a first examination at younger ages than children with no PF, and those predisposed to CNS tumours received higher cumulative brain doses. These results confirm the need to consider the existence of these PF in estimating the cancer risks potentially induced by CT scans. Indeed, the preliminary estimates of ERR associated with CT exposures were reduced by $17-56 \%$ (based on a 2 -year exclusion period), depending on the site of cancer, after adjusting the risk estimates for PF (Table 5).

Adjusted ERR per mGy was 0.012 (95\% CI -0.013 to 0.037$)$ for CNS cancer, 0.047 (95\% CI -0.065 to 0.159 ) for leukaemia, and 0.008 (95\% CI -0.057 to 0.073 ) for lymphoma at the end of a median follow-up of 4 years (median attained age $=9$ years, 2 -year exclusion period) (Table 5). Extending the exclusion period beyond 2 years substantially reduced the risk estimates of CNS cancer, a finding suggesting that an indication bias persists even after adjustment for PF. A mean duration of follow-up of 4 years was nevertheless too short to provide any conclusive results about radiation-induced risks in the study. Indeed, a long latency period (at least 5 years) is usually assumed for radiation-induced CNS cancer, and excess risk of leukaemia may be expressed $>25$ years after exposure (UNSCEAR, 2013). For hematopoietic tumours, the estimates were also limited by the small range of cumulative RBM doses. In addition, the interpretation of the lymphoma results remains uncertain as inconsistent estimates were obtained in the sensitivity analyses (Supplementary Table 7).

The ERR estimated here for leukaemia, without any adjustment for PF (Table 5), appears compatible with the estimates from the UK study (Pearce et al, 2012) for children under 10 years of age at the first scan. Our results for CNS cancer are also very similar to those obtained from the Australian study with a 1-year exclusion period (Mathews et al, 2013). Here, however, the excess risks diminished markedly as the exclusion period increased, resulting in estimates much lower than those published from the UK study after a 5-year exclusion period (Pearce et al, 2012). The excess risk of lymphoma is compatible with the most recent findings for survivors of the Hiroshima and Nagasaki atom bombs (ERR per mGy for non-Hodgkin lymphoma (NHL) was $>0.02$ in men when attained age at exposure was $<25$ years (Hsu et al, 2013)). The increased risk among boys observed in our study (Supplementary Table 6) is also consistent with all previous estimations, although there is little evidence so far that NHL may be radiation induced, and none for Hodgkin disease (UNSCEAR, 2013).

This study made it possible to assess for the first time the cancer risks associated with exposures to $\mathrm{CT}$ scans while taking into 
account major PF, including rare genetic defects and acquired immune deficiencies. The results emphasise that these factors affected the estimation of radiation-related risks during the first years after childhood CT scans. Adjusting the analyses for only one single-risk factor showed that none of them alone explained the decrease in ERRs. Conditions other than principal risk factors such as NF1 and Down syndrome should be therefore considered, although they were rarer. Furthermore, the results may suggest a lower radiation-related risk in children with PF (Supplementary Table 6). The very small cases observed in each group of PF prevent nevertheless the interpretation of a potential modification of effect in the current study. In addition, a similar pattern observed for each outcome associated with various PF may not support a potential biological effect. Finally, quantifying the effect of adjustment of the estimated excess risk should provide useful information to support the interpretation of results from studies without medical diagnoses or history. It should, however, be noted that the indication bias is likely to be less important among populations exposed at older ages than it is here, or when the duration of follow-up would be increased. There would be indeed a lower prevalence of $\mathrm{PF}$ in such populations and a more frequent use of CT scans for other reasons than PF.

Reverse causation may have biased the estimates of excess risk of CNS cancer from CT scans. The decrease in the ERR as the exclusion period increased (Table 6) and for time since first examination $>5$ years (Supplementary Table 6) suggests that the excess risk was due to situations where signs of cancer initiation ultimately explained, rather than followed, the use of CT scans. Nonetheless, no such trends were observed for leukaemia or lymphoma when the exclusion period was extended. A major issue in the interpretation of results of studies of CT scans is therefore to be able to provide risk estimates that are not affected by the scans performed due to cancers only diagnosed later (UNSCEAR, 2013; Walsh et al, 2014). As observed here, numerous studies have reported short mean times from symptom onset to diagnosis of CNS tumours (except for ganglioglioma), as short as 4-20 weeks depending on histology (Brasme et al, 2012). However, the time to diagnosis may exceed several years; for instance, $15 \%$ of the cases reported here had a time to diagnosis $>3$ years. After removing CT exposures after the date of the first symptoms, the ERR per mGy (adjusted for PF) of CNS tumours was 0.007 (95\% CI - 0.013 to 0.028 ), which suggests that a 2 -year exclusion period would not be sufficient for estimating unbiased radiation-induced risk. This estimate is consistent with the excess risk found for the Hiroshima and Nagasaki survivors exposed before the age of 15 years (ERR $\mathrm{mGy}-1=0.003$ (95\% CI 0.001-0.007) through the age of 50 years, according to the data used in (Preston et al, 2007), especially when considering the decrease in excess risk with attained age (Preston et al, 2002). Analyses restricted to exposures before the onset of first symptoms may thus provide estimates free of indication bias and thus help to determine appropriate exclusion periods to compensate for the unavailability of data about the indication of examinations.

Here, we devoted substantial effort to the estimation of the cumulative organ doses using $>900$ radiology protocols from the participating departments. The risk estimation is thus based on detailed French practices in paediatrics and reflects their variability over time among 23 radiology departments. From those protocols, organ dose were estimated using a CT dosimetry method based on Monte Carlo radiation transport (Lee et al, 2012), which is reported to provide more accurate estimations than older numerical tools, as the body contour and internal anatomy of patients are described by realistic paediatric phantoms (Lee et al, 2010). Dose estimation is thus thought to be as accurate as possible, although the technical parameters actually used at each image acquisition may vary from the protocol. Note that doses may have been reduced since the early 2000s, thanks to technological advances in CT and better optimisation of procedures. Uncertainties in exposure assessment remain, however, because of missing doses for CT examinations with unknown anatomical areas $(3.4 \%$ of all examinations in the participating departments), their performance in radiology departments not involved in the study, or because of incomplete storage of radiology data. In addition, assessment of the cohort's exposure to other diagnostic examinations was not possible. A previous study showed, however, that CT accounted for $83 \%$ of the dose from all diagnostic examinations of children exposed to CT scans in France (Etard et al, 2014). Although undefined doses would account for only a limited proportion of the total exposure from diagnostic procedures, we cannot rule out their possible effect on risk estimates. Sensitivity analyses show that a bias in risk estimation due to underascertainment of cases is unlikely (Supplementary Table 7).

Overall, the results reported here showed that studies estimating cancer risks after CT scans should consider the reason for these examinations to obtain convincing risk estimates. By extending the follow-up, the Cohorte Enfant Scanner should be able to provide more robust risk estimates in the future and to investigate whether a confounding bias related to the PFs persists at older ages. This cohort, as well as the UK study mentioned above, is participating in the Epi-CT collaborative project that includes nine national cohorts intended to obtain powerful results about cancer risks after CT scans and aims at enhancing strategies to optimise CT procedures. The Epi-CT project is focusing especially on exposure assessment and consideration of the uncertainties in dose estimation for risk analyses (Thierry-Chef et al, 2013). Valuable information (although for higher exposure levels) could also be obtained by studies on interventional procedures that use X-rays to treat benign conditions, especially as the indication for treatment is generally known with precision (Baysson et al, 2013). In clinical practice, all of those results should help to determine the situations in which the expected benefits do not outweigh the risks and clarify the information given to patients and parents. So far, no evidence has invalidated the risk predictions extrapolated from studies at high doses under the linear dose-response assumption. The promotion of the optimisation of CT procedures and the use, as often as possible, of nonirradiating techniques such as magnetic resonance imaging must continue, especially in paediatrics.

\section{ACKNOWLEDGEMENTS}

We are grateful to the radiologists, clinicians, physicists and administrators working in the participating hospitals who took so much of their time to provide us with the necessary radiology and clinical data: N Andreu, F Clémenceau, D Loisel, B Ory, D Weil (CHU Angers), J-M Garcier, J Guersen, S Mangin (CHU Clermont-Ferrand), S Baron, J Charbonnier, C Gaborit, D Sirinelli (CHU Tours), J-M Chave, E Chirpaz, O Fels, JF Rouanet (CHU La Réunion), N Boutry, A Bruandet, G Potier (CHU Lille), D Defez, Perrot, M Teisseire (CHU Lyon), B Bourlière, P Petit, C Seyler (CHU Marseille), M Saguintaah (CHU Montpellier), M Balde, F Collignon, M-A Galloy, E Pozza, E Schmitt (CHU Nancy), B Dupas, T Lefrançois, M Salaud, N Surer (CHU Nantes), C Barat, C Bertini, M Hajjar (CHU Bordeaux), N Baray, M-A Perrier, H Daubert, L Froment (CHU Rouen), S Dupont, B Giachetto, L Molinier, J Vial (CHU Toulouse), A Bouette, P Chambert (CHU Armand Trousseau-Paris), F Brunelle (CHU Necker-EnfantsMalades-Paris), E Dion (CHU Louis Mourier-Colombes), J Costa, G Sebag (CHU Robert Debré-Paris), G Khalifa (CHU Saint-Vincent de Paul-Paris), J Betout, E Maupu (APHP Siège), D Musset (CHU Antoine Béclère-Clamart), C Adamsbaum, S Franchi, D Pariente (CHU Bicêtre), N Sellier (CHU Jean 
Verdier-Bondy). We also warmly thank E N'Guyen, N Simon, B Lacour and J Clavel (Registre National des Cancers de l'Enfant) for their valuable help in providing data about cancer diagnoses. The research leading to these results has received funding from $\mathrm{La}$ Ligue contre le cancer (PRE09/MOB), the French National Cancer Institute (INCa) (2011-1-PL-SHS-01-IRSN-1), and the European Union's Seventh Programme for research, technological development and demonstration under Grant Agreement No 269912-EPI-CT: epidemiological study to quantify risks for paediatric-computerised tomography and to optimise doses. As the methodology for dose assessment applied for the present study differs to this one defined within the Epi-CT project (http://epi-ct.iarc.fr/), this paper does not necessarily reflect the results that will be obtained in the collaborative project from the use of French exposure data. The use of the personal data for this study was approved by the Commission Nationale Informatique et Libertés, responsible for enforcement of data privacy laws in France (approval ID 908354).

\section{CONFLICT OF INTEREST}

The authors declare no conflict of interest.

\section{REFERENCES}

Baysson H, Rehel JL, Boudjemline Y, Petit J, Girodon B, Aubert B, Laurier D, Bonnet D, Bernier MO (2013) Risk of cancer associated with cardiac catheterization procedures during childhood: a cohort study in France. BMC Public Health 13: 266.

Bernier MO, Mezzarobba M, Maupu E, Caer-Lorho S, Brisse HJ, Laurier D, Brunelle F, Chatellier G (2012a) [Role of French hospital claims databases from care units in epidemiological studies: the example of the "Cohorte Enfant Scanner" study]. Rev Epidemiol Sante Publique 60(5): 363-370.

Bernier MO, Rehel JL, Brisse HJ, Wu-Zhou X, Caer-Lorho S, Jacob S, Chateil JF, Aubert B, Laurier D (2012b) Radiation exposure from CT in early childhood: a French large-scale multicentre study. $\mathrm{Br} J$ Radiol 85(1009): 53-60.

Brasme JF, Morfouace M, Grill J, Martinot A, Amalberti R, Bons-Letouzey C, Chalumeau M (2012) Delays in diagnosis of paediatric cancers: a systematic review and comparison with expert testimony in lawsuits. Lancet Oncol 13(10): e445-e459.

Brenner DJ, Hall EJ (2007) Computed tomography-an increasing source of radiation exposure. $N$ Engl J Med 357(22): 2277-2284

Brenner DJ, Sachs RK (2006) Estimating radiation-induced cancer risks at very low doses: rationale for using a linear no-threshold approach. Radiat Environ Biophys 44(4): 253-256.

Breslow NE, Day NE (1987) Statistical methods in cancer research. Volume II-the design and analysis of cohort studies. IARC Sci Publ 82: $1-406$.

Calandrino R, Ardu V, Corletto D, del Vecchio A, Origgi D, Signorotto P, Spinelli A, Tosi G, Bolognesi A, Cariati M, Kluzer A, Muscarella S (2013) Evaluation of second cancer induction risk by CT follow-up in oncological long-surviving patients. Health Phys 104(1): 1-8.

Dang-Tan T, Franco EL (2007) Diagnosis delays in childhood cancer: a review. Cancer 110(4): 703-713.

Etard C, Sinno Tellier S, Empereur-Bissonnet P, Aubert B (2012) French population exposure to ionizing radiation from diagnostic medical procedures in 2007. Health Phys 102(6): 670-679.

Etard C, Aubert B, Mezzarobba M, Bernier MO (2014) Exposure of the French paediatric population to ionising radiation from diagnostic medical procedures in 2010. Pediatric Radiol; e-pub ahead of print 17 July 2014; doi:10.1007/s00247-014-3065-2.

Hall EJ, Brenner DJ (2012) Cancer risks from diagnostic radiology: the impact of new epidemiological data. Br J Radiol 85(1020): e1316-e1317.

Hsu WL, Preston DL, Soda M, Sugiyama H, Funamoto S, Kodama K, Kimura A, Kamada N, Dohy H, Tomonaga M, Iwanaga M, Miyazaki Y, Cullings HM, Suyama A, Ozasa K, Shore RE, Mabuchi K (2013) The incidence of leukemia, lymphoma and multiple myeloma among atomic bomb survivors: 1950-2001. Radiat Res 179(3): 361-382.
Huang WY, Muo CH, Lin CY, Jen YM, Yang MH, Lin JC, Sung FC, Kao CH (2014) Paediatric head CT scan and subsequent risk of malignancy and benign brain tumour: a nation-wide population-based cohort study. Br J Cancer 110(9): 2354-2360.

Ivanov VK, Tsyb AF, Mettler FA, Menyaylo AN, Kashcheev VV (2012) Methodology for estimating cancer risks of diagnostic medical exposure: with an example of the risks associated with computed tomography. Health Phys 103(6): 732-739.

Journy N, Ancelet S, Rehel JL, Mezzarobba M, Aubert B, Laurier D, Bernier MO (2014) Predicted cancer risks induced by computed tomography examinations during childhood, by a quantitative risk assessment approach. Radiat Environ Biophys 53(1): 39-54.

Krille L, Zeeb H, Jahnen A, Mildenberger P, Seidenbusch M, Schneider K, Weisser G, Hammer G, Scholz P, Blettner M (2012) Computed tomographies and cancer risk in children: a literature overview of CT practices, risk estimations and an epidemiologic cohort study proposal. Radiat Environ Biophys 51(2): 103-111.

Lacour B, Guyot-Goubin A, Guissou S, Bellec S, Desandes E, Clavel J (2010) Incidence of childhood cancer in France: National Children Cancer Registries, 2000-2004. Eur J Cancer Prev 19(3): 173-181.

Lee C, Kim KP, Long DJ, Bolch WE (2012) Organ doses for reference pediatric and adolescent patients undergoing computed tomography estimated by Monte Carlo simulation. Med Phys 39(4): 2129-2146.

Lee C, Lodwick D, Hurtado J, Pafundi D, Williams JL, Bolch WE (2010) The UF family of reference hybrid phantoms for computational radiation dosimetry. Phys Med Biol 55(2): 339-363.

Long DJ, Lee C, Tien C, Fisher R, Hoerner MR, Hintenlang D, Bolch WE (2013) Monte Carlo simulations of adult and pediatric computed tomography exams: validation studies of organ doses with physical phantoms. Med Phys 40(1): 013901.

Mathews JD, Forsythe AV, Brady Z, Butler MW, Goergen SK, Byrnes GB, Giles GG, Wallace AB, Anderson PR, Guiver TA, McGale P, Cain TM, Dowty JG, Bickerstaffe AC, Darby SC (2013) Cancer risk in 680,000 people exposed to computed tomography scans in childhood or adolescence: data linkage study of 11 million Australians. BMJ 346: f2360.

Mettler FA, Thomadsen BR, Bhargavan M, Gilley DB, Gray JE, Lipoti JA, McCrohan J, Yoshizumi TT, Mahesh M (2008) Medical radiation exposure in the U.S. in 2006: preliminary results. Health Phys 95(5): 502-507.

Meulepas JM, Ronckers CM, Smets AM, Nievelstein RA, Jahnen A, Lee C, Kieft M, Lameris JS, van Herk M, Greuter MJ, Jeukens CR, van Straten M, Visser O, van Leeuwen FE, Hauptmann M (2014) Leukemia and brain tumors among children after radiation exposure from CT scans: design and methodological opportunities of the Dutch Pediatric CT Study. Eur J Epidemiol 29(4): 293-301.

Miglioretti DL, Johnson E, Williams A, Greenlee RT, Weinmann S, Solberg LI, Feigelson HS, Roblin D, Flynn MJ, Vanneman N, Smith-Bindman R (2013) The use of computed tomography in pediatrics and the associated radiation exposure and estimated cancer risk. JAMA Pediatr 167(8): 700-707.

Mothersill C, Seymour C (2013) Uncomfortable issues in radiation protection posed by low-dose radiobiology. Radiat Environ Biophys 52(3): 293-298.

Pearce MS, Salotti JA, Little MP, McHugh K, Lee C, Kim KP, Howe NL, Ronckers CM, Rajaraman P, Sir Craft AW, Parker L, Berrington de Gonzalez A (2012) Radiation exposure from CT scans in childhood and subsequent risk of leukaemia and brain tumours: a retrospective cohort study. Lancet 380(9840): 499-505.

Preston D, Lubin J, Pierce DA, McConney M (1993) Epicure Users Guide. Hirosoft: Seattle, WA, USA.

Preston DL, Ron E, Tokuoka S, Funamoto S, Nishi N, Soda M, Mabuchi K, Kodama K (2007) Solid cancer incidence in atomic bomb survivors: 1958-1998. Radiat Res 168(1): 1-64.

Preston DL, Ron E, Yonehara S, Kobuke T, Fujii H, Kishikawa M, Tokunaga M, Tokuoka S, Mabuchi K (2002) Tumors of the nervous system and pituitary gland associated with atomic bomb radiation exposure. J Natl Cancer Inst 94(20): 1555-1563.

Preston RJ, Boice Jr JD, Brill AB, Chakraborty R, Conolly R, Hoffman FO, Hornung RW, Kocher DC, Land CE, Shore RE, Woloschak GE (2013) Uncertainties in estimating health risks associated with exposure to ionising radiation. J Radiol Prot 33(3): 573-588.

Shrimpton PC, Jones DG, Hillier MC (1991) Survey of CT practice in the UK; Part 2: Dosimetric aspects. National Radiological Protection Board: London, UK. 
Thierry-Chef I, Dabin J, Friberg EG, Hermen J, Istad TS, Jahnen A, Krille L, Lee C, Maccia C, Nordenskjold A, Olerud HM, Rani K, Rehel JL, Simon SL, Struelens L, Kesminiene A (2013) Assessing organ doses from paediatric CT scans-a novel approach for an epidemiology study (the EPI-CT study). Int J Environ Res Public Health 10(2): 717-728.

UNSCEAR (2013) Report of the United Nations Scientific Committee on the Effects of Atomic Radiation. UNSCEAR 2013 Report. Volume II. Scientific Annex B-Effects of Radiation Exposure of Children. United Nations: New York, NY, USA.
Walsh L, Shore R, Auvinen A, Jung T, Wakeford R (2014) Risks from CT scans-what do recent studies tell us? J Radiol Prot 34: 1.

This work is published under the standard license to publish agreement. After 12 months the work will become freely available and the license terms will switch to a Creative Commons AttributionNonCommercial-Share Alike 3.0 Unported License.

Supplementary Information accompanies this paper on British Journal of Cancer website (http://www.nature.com/bjc) 